\title{
RASSFIA hypermethylation is associated with ASXLI mutation and indicates an adverse outcome in non-M3 acute myeloid leukemia
}

This article was published in the following Dove Press journal:

OncoTargets and Therapy

22 August 2017

Number of times this article has been viewed

\author{
Fang Liu',* \\ Ming Gong ${ }^{2, *}$ \\ Li Gao ${ }^{2, *}$ \\ Xiaoping $\mathrm{Cai}^{3}$ \\ Hui Zhang ${ }^{2}$ \\ Yigai $\mathrm{Ma}^{2}$
}

'Department of Oncology, Chinese PLA General Hospital, ${ }^{2}$ Department of Hematology, China-Japan Friendship Hospital, ${ }^{3}$ Department of Geriatric Medicine, Army General Hospital, Beijing, People's Republic of China

*These authors contributed equally to this work

Correspondence: Yigai Ma

Department of Hematology, China-Japan Friendship Hospital, East Yinghua Road,

Beijing, People's Republic of China

Tel +86 I39 I028 6029

Fax +86 I0 8420 5522

Email dr_myg@163.com

Fang Liu

Department of Oncology, Chinese PLA General Hospital, Fuxing Road, Beijing,

People's Republic of China

Tel +86 I35 20469875

Fax +86 1066937005

Email liufangfsq@|63.com
Objective: The purpose of this study was to evaluate the frequency of $R A S S F 1 A$ hypermethylation in patients with acute myeloid leukemia (AML), in an attempt to modify the current molecular model for disease prognosis.

Materials and methods: Aberrant RASSF1A promoter methylation levels were assessed in 226 newly diagnosed non-M3 AML patients and 30 apparently healthy controls, by quantitative methylation-specific polymerase chain reaction. Meanwhile, RASSF1A mRNA levels were detected by real-time quantitative polymerase chain reaction. Furthermore, hematological characteristics, cytogenetic abnormalities, and genetic aberrations were assessed. Finally, associations of RASSF1A hypermethylation with clinical outcomes were evaluated.

Results: RASSF1A hypermethylation was observed in $23.0 \%$ of patients with non-M3 AML (52/226), but not in controls. Meanwhile, hypermethylation of the RASSF1A promoter was significantly associated with $A S X L 1$ mutation. Furthermore, the log-rank test revealed that RASSF $1 A$ hypermethylation indicated decreased relapse-free survival (RFS) and overall survival (OS) in patients with non-M3 AML $(P=0.012$ and $P=0.014$, respectively). In multivariate analysis, $R A S S F 1 A$ hypermethylation was an independent prognostic factor for RFS $(P=0.040)$, but not for OS $(P=0.060)$.

Conclusion: Hypermethylation of the RASSF $1 A$ promoter is associated with ASXL1 mutation in non-M3 AML patients, likely indicating poor outcome. These findings provide a molecular basis for stratified diagnosis and prognostic evaluation.

Keywords: RASSF1A, hypermethylation, acute myeloid leukemia, clinical outcome, survival

\section{Introduction}

Acute myeloid leukemia (AML), a clonal oncohematological disorder, is characterized by disrupted maturation and programmed cell death (apoptosis), accompanied by uncontrolled proliferation of immature hematopoietic progenitor cells and subsequent suppression of functionally normal hematopoiesis. ${ }^{1,2}$ Recent advances in genetics have greatly improved our understanding of the molecular mechanisms underlying leukemic transformation. ${ }^{3,4}$ DNA methylation of $\mathrm{CpG}$ islands within gene promoter regions, the most extensively and systematically studied epigenetic mechanism, is crucial for gene regulation during normal hematological cell development. ${ }^{5}$ Hypermethylation within the promoters of anti-oncogenes appears to be especially common in some or all types of human hematopoietic neoplasms..$^{6-8}$ To date, many genes have been shown to contribute to leukemogenesis via epigenetic silencing. Our previous reports indicated aberrant hypermethylation of CTNNA1, CHFR1, and miR-193a in several myeloid malignancies. ${ }^{9-11}$ 
$R A S S F 1 A$, considered an important tumor suppressor gene, is located on chromosome $3 \mathrm{p} 21 .{ }^{12}$ RASSF $1 A$ represents potential Ras effectors and plays vital biological roles in cancer progression. ${ }^{13}$ Several studies have shown that $R A S S F 1 A$ is expressed in normal tissues, including hematopoietic cells; however, its expression is significantly lower in human cancer. ${ }^{14}$

The current study aimed to assess the methylation levels of the RASSF1A promoter by quantitative methylationspecific polymerase chain reaction (qMS-PCR) in bone marrow (BM) biopsy specimens from non-M3 AML patients. The overarching objective was to identify a subset of patients who might harbor aberrant methylation levels, and in a complementary approach, to comparatively examine the clinical characteristics of these patients. In addition, chromosomal abnormalities and gene mutations known to be associated with AML were assessed for their associations with RASSF $1 A$ hypermethylation. Furthermore, to predict the clinical impact of our findings, we evaluated relapse-free survival (RFS) and overall survival (OS) in relation to $R A S S F 1 A$ methylation levels in the study population.

\section{Materials and methods}

\section{Patients}

This study included 226 newly diagnosed patients with non-M3 AML visiting the Chinese PLA General Hospital and China-Japan Friendship Hospital, from July 2006 to March 2015, and 30 healthy controls. Written informed consent was obtained from each subject for sample preservation and genetic assays. The study was approved by the ethics committees of the Chinese PLA General Hospital and
China-Japan Friendship Hospital. BM samples were collected during routine clinical examination, and those with more than $50 \%$ blastocysts, identified by morphologic assessment, were selected. The clinical characteristics of patients are described in Table 1. All patients with non-M3 AML received intensive induction therapy with high-dose cytarabine-based regimens or monotherapy with decitabine (demethylating treatment) followed by consolidation therapy. Twenty-nine patients underwent allogeneic hematopoietic stem cell transplantation, and 26 received autologous hematopoietic stem cell transplantation.

\section{Clinical end points}

Complete remission (CR) was defined as no anemia, bleeding, infection, leukemic cell infiltration, circulating leukemic blastocysts, or evidence of extramedullary leukemia, with a recovery of morphologically normal BM and blood cell amounts. In addition, BM cells and primitive promyelocytic-stage cells (or immature cells) were $<5 \%$, with normal erythroid-megakaryocyte system. Relapse was defined as $\geq 5 \%$ BM blastocysts, circulating leukemic blastocysts, or the emergence of extramedullary leukemic cells. OS was determined from leukemia diagnosis to death, censoring patients alive at the last follow-up. RFS was determined from the date of CR to relapse or death from any cause, censoring patients alive at the last follow-up.

\section{DNA isolation, bisulfite modification, and $\mathrm{qMS}-\mathrm{PCR}$}

Genomic DNA was extracted and purified from BM specimens with Genomic DNA Purification Kit (Promega,

Table I Analysis of clinical characteristics and outcome in two groups

\begin{tabular}{|c|c|c|c|c|}
\hline Variables & Total & Hypermethylation (n) & Non-methylation (n) & $P$-value \\
\hline Patients (N) & 226 & 52 & 174 & NS \\
\hline Age & $43(12-94)$ & $38(14-87)$ & $43(12-94)$ & 0.229 \\
\hline Sex & $137(\mathrm{M}) / 89(\mathrm{~F})$ & $35(\mathrm{M}) / 17(\mathrm{~F})$ & $102(\mathrm{M}) / 72(\mathrm{~F})$ & $0.26 \mathrm{I}$ \\
\hline M2 & 54 & 11 & 43 & 0.597 \\
\hline M4 & 43 & 15 & 32 & 0.103 \\
\hline M5 & 60 & 14 & 46 & 0.944 \\
\hline Unclassified AML & 41 & 8 & 33 & 0.557 \\
\hline WBC $\left(\times 10^{9} / L\right)$ & $21.74(1.9-76.3)$ & $19.95(1.98-76.3)$ & $22.32(1.9-74)$ & 0.443 \\
\hline Hemoglobin $(\mathrm{g} / \mathrm{L})$ & $72(26-13 \mid)$ & $73(34-131)$ & $71(26-126)$ & 0.529 \\
\hline Platelets ( $\left.\times 10^{9} / \mathrm{L}\right)$ & $4 I(I-146)$ & $43(I-\mid 4 I)$ & $40(4-146)$ & 0.414 \\
\hline Marrow blasts (\%) & $70(26-98)$ & $68(39-95)$ & 71 (26-98) & 0.179 \\
\hline \multicolumn{5}{|l|}{ Induction therapy } \\
\hline IA & 70 & 15 & 55 & 0.705 \\
\hline DA & 84 & 24 & 60 & 0.126 \\
\hline MA & 72 & 13 & 59 & 0.226 \\
\hline Allo-HSCT & 29 & 8 & 21 & 0.524 \\
\hline Auto-HSCT & 26 & 5 & 21 & 0.627 \\
\hline
\end{tabular}

Abbreviations: NS, nonsignificant; AML, acute myeloid leukemia; WBC, white blood cell; IA, idarubicin and cytarabine; DA, daunorubicin and cytarabine; MA, mitoxantrone and cytarabine; allo-HSCT, allogeneic hematopoietic stem cell transplantation; auto-HSCT, autologous hematopoietic stem cell transplantation. 
Madison, WI, USA). Then, $1 \mu \mathrm{g}$ of genomic DNA was treated with sodium bisulfate using EpiTect Kit (Qiagen, Hilden, Germany). Bisulfite-treated DNA was amplified by qMSPCR using primers and probes specific for RASSF $1 A$ and MYOD1 (reference gene) (shown in Table S1). Polymerase chain reaction (PCR) was carried out in a $40 \mu \mathrm{L}$ volume with $20 \mu \mathrm{L}$ MethyLight Master Mix (Qiagen), $0.25 \mu \mathrm{M}$ of each primer, RASSF1A or MYOD1 gene probes, and $20 \mathrm{ng}$ bisulfite-treated DNA. PCR conditions consisted of an initial denaturation step of $95^{\circ} \mathrm{C}$ for 5 minutes, followed by 40 cycles of denaturation for 15 seconds at $95^{\circ} \mathrm{C}$ and annealing for 60 seconds at $61^{\circ} \mathrm{C}$. Standard curves were established for RASSF1A and MYOD1 using 10-fold serial dilutions of five different plasmid concentrations. Relative methylation levels of RASSF $1 A$ were calculated by the ratio of $R A S S F 1 A$ copies to that of MYOD1.

\section{Karyotype analysis and fluorescence in situ hybridization (FISH)}

A total of 226 patients were submitted to cytogenetic analysis of BM samples at diagnosis by the direct method or 24-hour culture. The cytogenetic assays were performed independently by at least two cytogenetic technicians or pathologists. Metaphase chromosomes were assessed by G-banding, with chromosomal abnormalities presented according to the International System for Human Cytogenetic Nomenclature. ${ }^{15}$ Simultaneous presentation of at least three unrelated cytogenetic abnormalities in one clone was defined as complex cytogenetic abnormalities. Cytogenetic abnormalities were divided into favorable, intermediate, and unfavorable karyotype groups, based on published criteria accepted by the Southwest Oncology Group (SWOG). ${ }^{16}$ Besides, -5/5q-, -7/7q-, inv(16)/t(16;16), and 11q23 rearrangement abnormalities were confirmed by FISH.

\section{Real-time quantitative polymerase chain reaction (RT-qPCR)}

Total RNA was isolated from BM samples from patients with non-M3 AML at diagnosis, with the Qiazol isolation reagent (Qiagen). Then, cDNA was obtained using a reverse transcription kit (Promega). Quantification of RASSF1A and $A B L 1$ transcripts was performed by RT-qPCR with specific primers and probes (Table S2). The PCR volume was $40 \mu \mathrm{L}$, including $20 \mu \mathrm{L}$ TaqMan Universal Master Mix (Life Technologies), $0.25 \mu \mathrm{M}$ of each primer, RASSF $1 A$ and $A B L 1$ gene probes, and $20 \mathrm{ng}$ cDNA. The PCR program comprised 40 cycles of denaturation for 15 seconds at $95^{\circ} \mathrm{C}$ and annealing for 60 seconds at $60^{\circ} \mathrm{C}$. Standard curves were generated for the RASSF $1 A$ and $A B L 1$ genes by 10 -fold serial dilutions of five different plasmid concentrations. Relative expression of RASSF $1 A$ was determined as the ratio of $R A S S F 1 A$ copies to that of $A B L 1$.

\section{Detection of gene mutations}

To assess the associations of gene mutations occurring in AML patients with the methylation status of the RASSF $1 A$ promoter region, DNA sequencing was conducted to detect NPM1, FLT3-ITD, ASXL1, IDH1, DNMT3A, RUNX1, U2AF1, TET2, SRSF2, NRAS, CEBPA, KIT, and SF3B1 with hyperfrequency-mutation sequences, as previously reported. ${ }^{9} 10,17-22$ The primers used for sequencing are shown in Table S3.

\section{Statistical analysis}

All statistical analyses were performed with the SPSS 18.0 software (SPSS, Chicago, IL, USA). Data were presented as median and range. Pearson chi-square and Fisher's exact tests were adopted to compare the patient groups. The associations of the methylation status of the RASSF1A promoter with clinical parameters were assessed by Pearson's and Spearman's rank correlations. Patients were followed up for a median time of 36 months (range, 5-100 months). The Kaplan-Meier method was used to estimate survival, and differences between groups were analyzed by log-rank test. To adjust for clinical and molecular prognostic variables, a multivariate Cox model was utilized to assess the associations of survival with age, chromosomal abnormalities, RASSF $1 A$ methylation level, and mutation status. For all analyses, $P<0.05$ was considered statistically significant.

\section{Results}

\section{DNA methylation status and RASSFIA gene expression in AML patients}

RASSF 1A gene promoter methylation levels were assessed in BM samples from 226 AML patients and 30 healthy donors. RASSF $1 A$ hypermethylation was found in $23 \%(52 / 226)$ of AML patients, but not in healthy donors. Among the 52 patients, median $R A S S F 1 A$ hypermethylation level was 1.0279 , ranging from 0.1967 to 5.336 . Gene expression analysis showed significantly decreased $R A S S F 1 A$ levels in patients with $R A S S F 1 A$ hypermethylation compared with the non-methylation group (Figure $1 \mathrm{~A}, P<0.001$ ). Moreover, there was a significant negative association of $R A S S F 1 A$ mRNA levels with hypermethylation in both patient groups (Figure 1B, $P=0.028, R=-0.364$ ). 

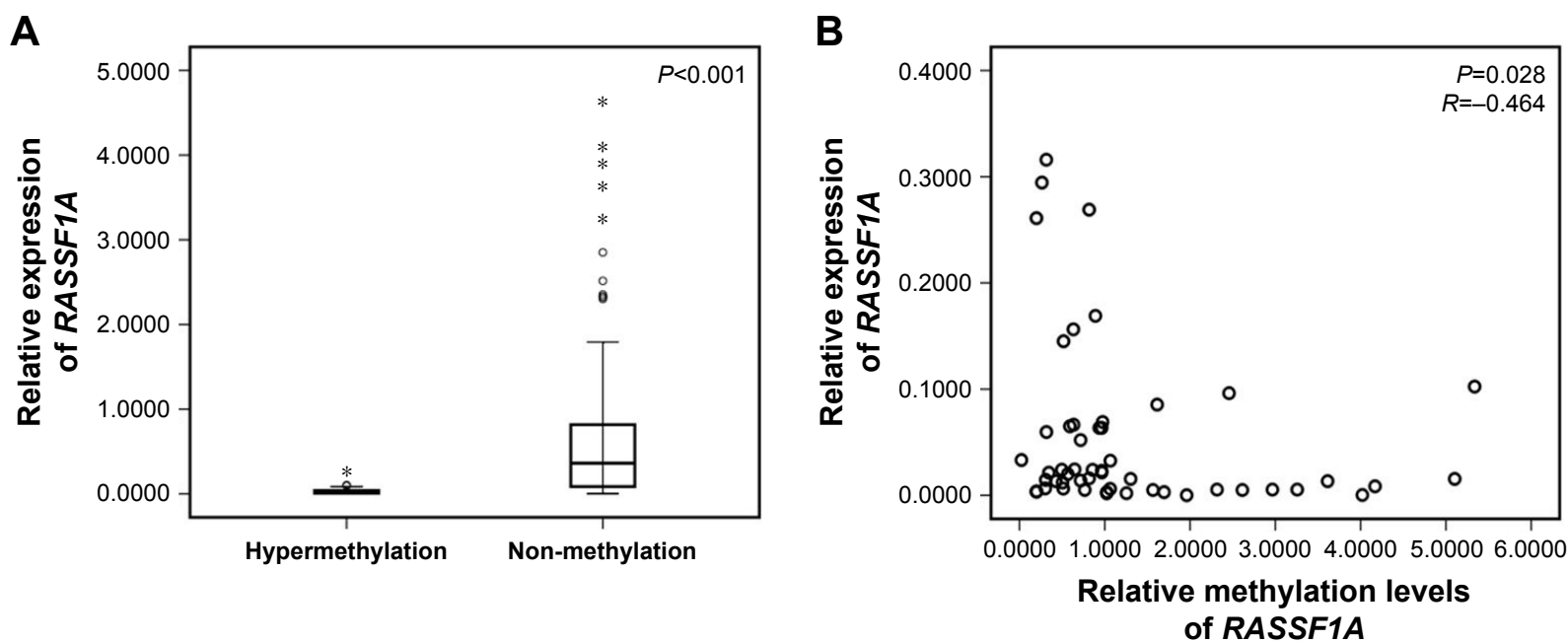

Figure I (A) Relative expression of the RASSFIA gene was detected in the patients with RASSFIA hypermethylation and the cases with non-methylation, and significant difference was found between the two groups. *Singular value. (B) There was a negative correlation between RASSFIA methylation levels and RASSFIA transcript levels $(R=-0.464, P=0.028)$.

\section{RASSFIA hypermethylation is associated with chromosomal abnormalities}

To further assess the cytogenetic abnormalities in both patient groups (with or without $R A S S F 1 A$ gene hypermethylation), various karyotypes were compared between the two groups.
As shown in Table 2, RASSF $1 A$ hypermethylation was highly associated with unfavorable chromosomal abnormalities $(P=0.049)$ and complex karyotype $(P=0.016)$. There were no significant differences in other karyotypes between the RASSF $1 A$ hypermethylation and non-methylation groups.

Table 2 Comparison of genetic alterations between patients with acute myeloid leukemia with or without hypermethylation of the RASSFIA promoter

\begin{tabular}{|c|c|c|c|c|}
\hline Variant & Total (n) & Hypermethylation (n) & Non-methylation (n) & $P$-value \\
\hline \multicolumn{5}{|l|}{ Cytogenetic risk ${ }^{\mathrm{a}}$} \\
\hline Favorable & 20 & 4 & 16 & 0.955 \\
\hline Intermediate & $15 \mid$ & 30 & 121 & 0.111 \\
\hline Unfavorable & 55 & 18 & 37 & 0.049 \\
\hline \multicolumn{5}{|c|}{ Cytogenetic characteristics ${ }^{b}$} \\
\hline$t(8 ; 21)$ & 12 & I & 11 & 0.374 \\
\hline $\operatorname{inv}(16) / t(16 ; 16)$ & 8 & 3 & 5 & 0.573 \\
\hline I Iq23 abnormalities & 15 & 6 & 9 & 0.193 \\
\hline Complex karyotype & 33 & 13 & 20 & 0.016 \\
\hline Normal karyotype & 122 & 23 & 99 & 0.108 \\
\hline \multicolumn{5}{|l|}{ Gene mutations ${ }^{c}$} \\
\hline IDHI & 23 & 7 & 16 & 0.372 \\
\hline$A S X L I$ & 22 & 9 & 13 & 0.036 \\
\hline FLT3 & 25 & 4 & 21 & 0.377 \\
\hline KIT & 8 & I & 7 & 0.771 \\
\hline TET2 & 16 & 4 & 12 & 0.846 \\
\hline SF3BI & 9 & I & 8 & 0.645 \\
\hline CEBPA & 11 & I & 10 & 0.449 \\
\hline DNMT3A & 19 & 7 & 12 & 0.225 \\
\hline NPMI & 49 & 10 & 39 & 0.625 \\
\hline NRAS & 13 & 2 & 11 & 0.739 \\
\hline SRSF2 & 13 & 3 & 10 & 0.995 \\
\hline U2AFI & 18 & 5 & 13 & 0.834 \\
\hline RUNXI & 16 & 5 & 11 & 0.162 \\
\hline
\end{tabular}

Notes: ${ }^{2}$ Cytogenetic abnormalities were grouped according to published criteria adopted by the Southwest Oncology Group as favorable, intermediate, and unfavorable. Favorable: inv(16)/t(16;16)/del(I6q), t(15;17) with/without secondary aberrations, $\mathrm{t}(8 ; 2 \mathrm{I})$ lacking del(9q), or complex karyotypes; unfavorable: del(5q)/-5, del(7q)/-7,

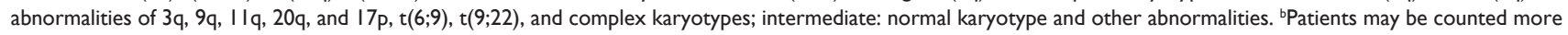
than once because of coexistence of more than one cytogenetic abnormality in the leukemic clone. 'Patients may be counted more than once because of coexistence of more than one mutation in the leukemic clone. 


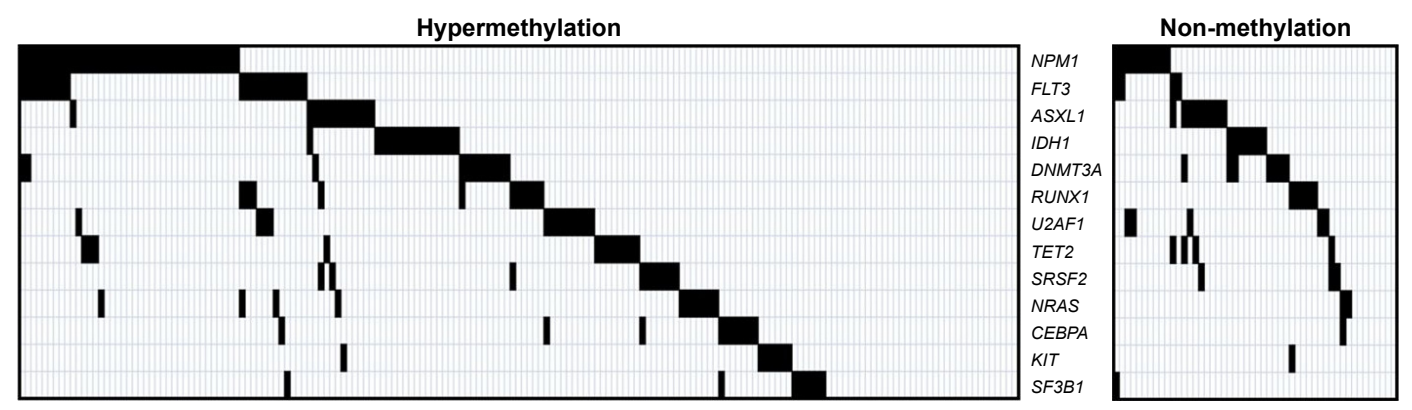

Figure 2 Spectrum of gene mutations in 226 non-M3 AML patients with hypermethylation and non-methylation of the RASSFIA gene.

\section{Patients with aberrant RASSFIA methylation show higher ASXLI mutation frequencies}

In the present study, $A S X L 1, C E B P A, D N M T 3 A, F L T 3$, IDH1, KIT, NPM1, NRAS, RUNX1, SF3B1, SRSF2, U2AF1, and TET2 mutations were assessed in all 226 patients with non-M3 AML. The mutation spectra in both hypermethylation and non-methylation patient groups are shown in Figure 2. As shown in Table 2, cases with aberrant RASSF1A methylation levels displayed a higher probability of $A S X L 1$ mutation ( $P=0.036$ ). In the present work, a total of 22 patients showed $A S X L 1$ mutations, including 9 and 13 in the hypermethylation and non-hypermethylation groups, respectively.

\section{Patients displaying aberrant RASSFIA methylation levels have adverse outcome}

In the present study, we evaluated RFS and OS in both patient groups (with or without RASSF1A hypermethylation) (Figure 3A and B). All 226 patients with AML were enrolled, with a median follow-up of 41 months (mean, 5-80 months). Interestingly, non-M3 AML patients with RASSF1A hypermethylation exhibited reduced RFS $(P=0.012)$ and OS $(P=0.014)$ compared with the non-hypermethylation group. To further assess the prognostic value of RASSF1A methylation levels, the patients were divided into two groups according to the 75th percentile of the initial transcript levels (Figure 3C and D). Consequently, 13 patients were assigned to the high methylation group, and the remaining to the low methylation group. Interestingly, patients with high RASSF1A methylation levels exhibited similar RFS $(P=0.968)$ and $O S$ ( $P=0.798$ ) compared to the low methylation group.

Hypermethylation of the RASSF1A gene was entered into a multivariate model with variables significantly associated with prognosis in univariate analysis in the present cohort. Interestingly, RASSF1A hypermethylation and U2AF1 mutation were independent prognostic factors for RFS, but not for OS (Table 3 ). Meanwhile, age $\geq 60$ years, unfavorable karyotype, RUNX1 mutation, FLT3-ITD, and DNMT3A mutation showed reduced RFS and OS.

\section{Discussion}

Recent studies have revealed that leukemic cells exhibit various genetic and epigenetic abnormalities that contribute not only to cell transformation but also to disease progression. These novel insights not only provide clues for diagnostic stratification and prognostic evaluation but also play a key role in the appropriate selection of individuals for suitable targeted therapy. ${ }^{23-25}$ DNA hypermethylation, which causes transcriptional repression, has recently emerged as one of the most frequent changes occurring in cancers, including hematopoietic tumors, and is associated with malignant transformation, making it an intriguing novel target for therapeutic targeting of leukemia. ${ }^{26}$ The use of irreversible DNA methyltransferase inhibitors, including 5-azacytidine (5-aza) and decitabine, appears to be a promising option for treating myeloid malignancies, including AML. ${ }^{27-29}$ RASSF $1 A$ is considered a candidate leukemia-suppressor gene; ${ }^{12,13}$ however, determining its exact effects on clinical outcome using BM samples from patients has been challenging. In addition, aberrant methylation levels of RASSF $1 A$ in a subpopulation of myeloid malignant patients were recently reported, but with no associations with gene mutations often detected in myeloid malignancies. ${ }^{30}$ Hence, in the present study, the associations of RASSF1A methylation with hematological findings, cytogenetic and genetic aberrations, and clinical outcomes in AML patients were assessed.

As shown above, DNA hypermethylation of the RASSF $1 A$ promoter was a frequent genetic event in patients with non-M3 AML. Johan et al demonstrated that RASSF $1 A$ promoter methylation is found in AML and myelodysplastic syndromes, by methylation-specific PCR. ${ }^{31}$ Meanwhile, Avramouli et al found that RASSF1AA methylation does not frequently occur in chronic myeloid leukemia. ${ }^{32}$ 
A

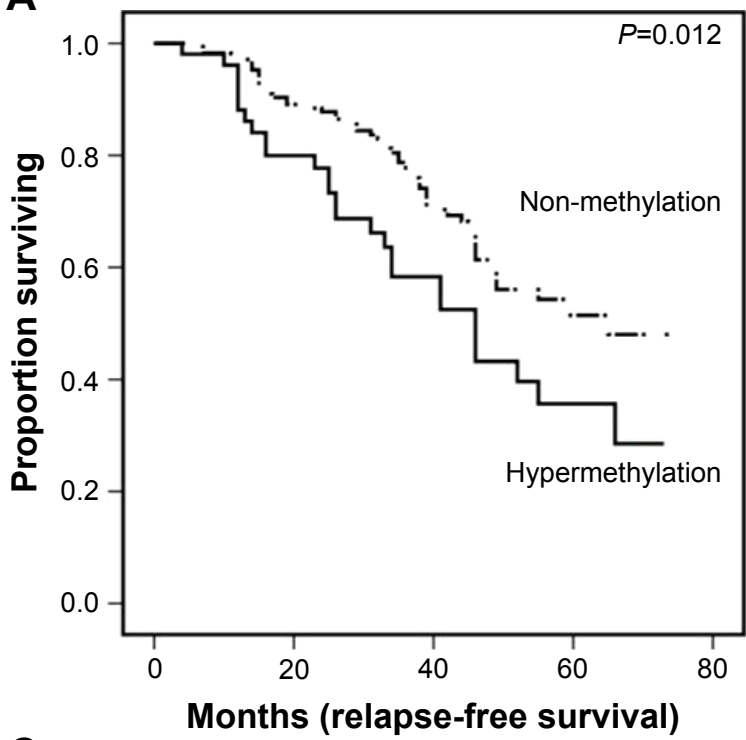

C

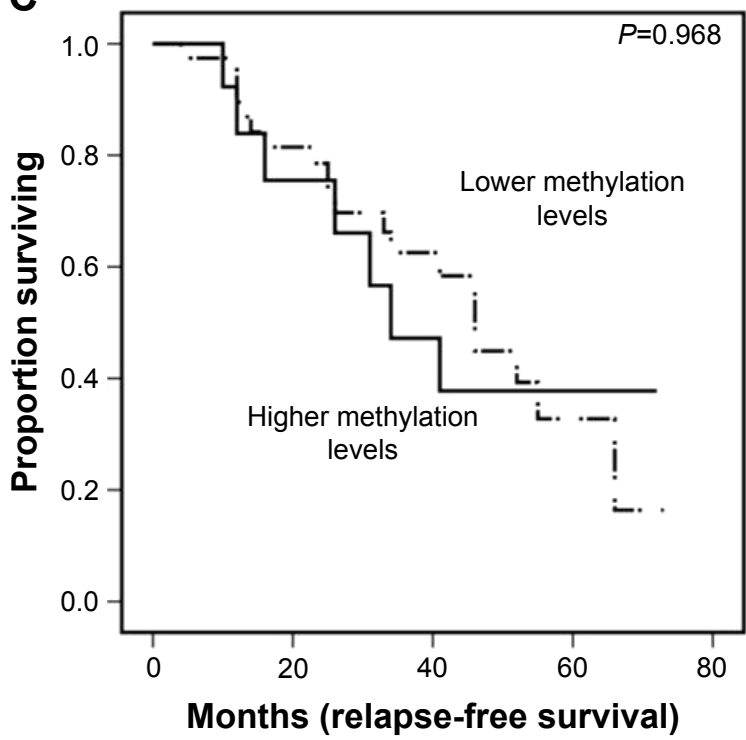

B
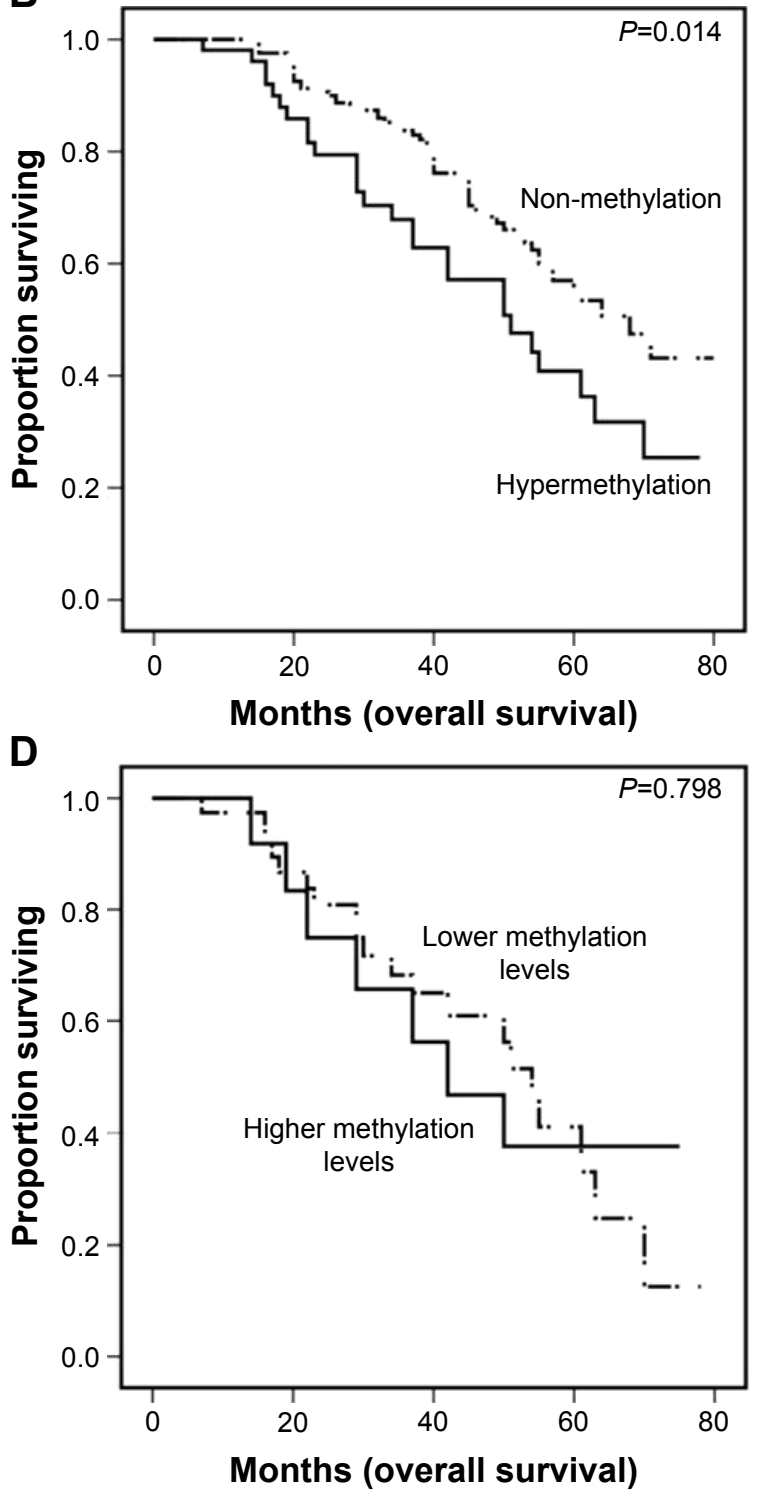

Figure 3 (A and B) Among non-M3 AML patients, those with RASSFIA hypermethylation ( $\mathrm{n}=52$ ) had inferior relapse-free survival and overall survival compared to those with no hypermethylation $(n=174)(P=0.012$ and $P=0.014$, respectively). ( $C$ and $\mathbf{D})$ Patients with higher $R A S S F I A$ methylation levels ( $n=13)$ did not show different relapse-free survival and overall survival compared to individuals with lower methylation levels $(n=39)(P=0.968$ and $P=0.798$, respectively).

Table 3 Univariate and multivariate analysis of clinical and molecular variables for RFS and OS in non-M3 AML patients

\begin{tabular}{|c|c|c|c|c|c|c|c|c|}
\hline \multirow[t]{3}{*}{ Variables } & \multicolumn{4}{|c|}{ Univariate analysis } & \multicolumn{4}{|c|}{ Multivariate analysis } \\
\hline & \multicolumn{2}{|l|}{ RFS } & \multicolumn{2}{|l|}{ os } & \multicolumn{2}{|l|}{ RFS } & \multicolumn{2}{|l|}{ OS } \\
\hline & $\begin{array}{l}P \text { - } \\
\text { value }\end{array}$ & OR $(95 \% \mathrm{Cl})$ & $\begin{array}{l}P \text { - } \\
\text { value }\end{array}$ & OR $(95 \% \mathrm{Cl})$ & $\begin{array}{l}P \text { - } \\
\text { value }\end{array}$ & OR $(95 \% \mathrm{Cl})$ & $\begin{array}{l}P \text { - } \\
\text { value }\end{array}$ & OR $(95 \% \mathrm{Cl})$ \\
\hline $\mathrm{Age}^{\mathrm{a}}$ & 0.006 & $2.730(1.739-4.286)$ & 0.009 & $2.720(1.734-4.267)$ & 0.002 & $2.540(1.522-4.238)$ & 0.005 & $2.536(1.516-4.242$ \\
\hline Unfavorable karyotype $^{b}$ & 0.041 & $1.617(1.021-2.562)$ & 0.058 & $1.60(0.985-2.473)$ & 0.033 & 1.701 (1.045-2.768) & $0.04 I$ & $1.663(1.022-2.706$ \\
\hline RASSFIA hypermethylation & 0.012 & $1.782(1.125-2.822)$ & 0.014 & 1.758 (I.1 I0-2.785) & 0.040 & $1.622(0.979-2.687)$ & 0.060 & $1.593(0.962-2.637$ \\
\hline ASXLI mutation & 0.008 & $2.238(1.237-4.052)$ & 0.007 & $2.277(1.257-4.123)$ & 0.058 & $1.863(0.978-3.547)$ & 0.083 & $1.780(0.927-3.417$ \\
\hline FLT3-ITD & 0.004 & 3.009 (1.735-5.533) & 0.004 & $3.078(1.725-5.493)$ & 0.021 & $3.518(1.921-6.442)$ & 0.025 & $3.510(1.907-6.460$ \\
\hline RUNXI mutation & 0.002 & 3.278 (1.563-6.877) & 0.001 & $3.34 \mid(1.592-7.010)$ & 0.005 & $3.078(1.407-6.733)$ & 0.004 & $3.179(1.46 \mid-6.995)$ \\
\hline DNMT3A mutation & 0.006 & $2.306(1.275-4.172)$ & 0.007 & $2.244(1.24 I-4.058)$ & 0.033 & $2.577(1.380-4.812)$ & 0.034 & $2.505(1.340-4.684$ \\
\hline U2AFI mutation & 0.011 & $2.295(1.214-4.338)$ & 0.011 & $2.273(1.203-4.295)$ & 0.036 & $2.122(1.05 I-4.286)$ & 0.052 & $2.018(0.994-4.097$ \\
\hline
\end{tabular}

Notes: aPatients aged $>60$ years vs others. Unfavorable cytogenetics vs others.

Abbreviations: RFS, relapse-free survival; OS, overall survival; OR, odds ratio; $\mathrm{Cl}$, confidence interval. 
However, whether RASSF1A methylation is associated with other genetic aberrations of myeloid malignancies remains unclear. In this study, the qMS-PCR approach was employed to detect RASSF1A gene methylation levels. To the best of our knowledge, this is the first report assessing RASSF $1 A$ gene methylation levels.

Besides, RASSF1A methylation was evaluated in all French-American-British subtypes included in the current study, with no specific phenotype found to be highly associated. In addition, patients with aberrant methylation levels showed no decreased CR rate or one-year OS (data not shown).

In the present study, cytogenetic aberrations and gene mutations associated with hematopoietic malignancies were assessed in the RASSF1A hypermethylation and nonhypermethylation groups. Close associations were found of RASSF $1 A$ hypermethylation with unfavorable chromosomal abnormalities and complex karyotype, which are considered poor cytogenetic markers in AML. ${ }^{16}$ These findings suggested that $R A S S F 1 A$ hypermethylation could be considered a novel prognostic marker for AML. However, the molecular mechanism underlying the association of $A S X L 1$ mutation with RASSF 1A hypermethylation remains unknown and requires deeper fundamental research. It is worth noting that $A S X L 1$ gene mutations are more frequent in patients with $R A S S F 1 A$ hypermethylation. Recent studies demonstrated that $A S X L 1$ mutation is a reliable marker of poor outcome in AML. ${ }^{33-35}$ However, such a finding was not obtained in this study, likely because only the high-frequency target sequence of ASXL1 was detected.

We also evaluated patient survival curves in association with $R A S S F 1 A$ hypermethylation. Interestingly, patients with RASSF 1A hypermethylation had reduced RFS compared with the non-methylation group, providing a theoretical basis for specific molecularly targeted therapy using demethylating agents.

In recent years, great progress has been made in understanding epigenetic changes in leukemia, providing a solid theoretical basis for molecular detection and diagnostic stratification, and shedding light on the development of hematologic disorders. ${ }^{36-38}$ RASSF $1 A$ was shown to act as a leukemia-associated gene, probably playing a vital role in the occurrence of AML and other hematopoietic malignancies.

\section{Conclusion}

In the current study, our analysis of $R A S S F 1 A$ promoter methylation status and its potential association with cytogenetic and molecular characteristics and clinical outcomes revealed vital points into the involvement of the $R A S S F 1 A$ gene in the pathogenesis of leukemia.

\section{Acknowledgments}

This study was supported by the National Natural Science Foundation of China (Grant No 81300425 and 81300450) and the Key Program of Capital Development Foundation (No 2007-2040).

\section{Disclosure}

The authors report no conflicts of interest in this work.

\section{References}

1. Ferrara F, Schiffer CA. Acute myeloid leukaemia in adults. Lancet 2013;381(9865):484-495.

2. Levine RL. Molecular pathogenesis of AML: translating insights to the clinic. Best Pract Res Clin Haematol. 2013;26(3):245-248.

3. Khaled S, Al Malki M, Marcucci G. Acute myeloid leukemia: biologic, prognostic and therapeutic insights. Oncology (Williston Park). 2016; 30(4):318-329.

4. Jabbour E, Cortes J, Ravandi F, O'Brien S, Kantarjian H. Targeted therapies in hematology and their impact on patient care: chronic and acute myeloid leukemia. Semin Hematol. 2013;50(4):271-283.

5. Pastore F, Levine RL. Epigenetic regulators and their impact on therapy in acute myeloid leukemia. Haematologica. 2016;101(3):269-278.

6. Conway O'Brien E, Prideaux S, Chevassut T. The epigenetic landscape of acute myeloid leukemia. Adv Hematol. 2014;2014:103175.

7. Hennessy BT, Garcia-Manero G, Kantarjian HM, Giles FJ. DNA methylation in haematological malignancies: the role of decitabine. Expert Opin Investig Drugs. 2003;12(12):1985-1993.

8. Schoofs T, Müller-Tidow C. DNA methylation as a pathogenic event and as a therapeutic target in AML. Cancer Treat Rev. 2011;37 Suppl 1: S13-S18.

9. Li M, Gao L, Li Z, et al. CTNNA1 hypermethylation, a frequent event in acute myeloid leukemia, is independently associated with an adverse outcome. Oncotarget. 2016;7(21):31454-31465.

10. Gao L, Liu F, Zhang H, Sun J, Ma Y. CHFR hypermethylation, a frequent event in acute myeloid leukemia, is independently associated with an adverse outcome. Genes Chromosomes Cancer. 2016;55(2): 158-168.

11. Li Y, Gao L, Luo X, et al. Epigenetic silencing of microRNA-193a contributes to leukemogenesis in $\mathrm{t}(8 ; 21)$ acute myeloid leukemia by activating the PTEN/PI3K signal pathway. Blood. 2013;121(3): 499-509.

12. van der Weyden L, Adams DJ. The Ras-association domain family (RASSF) members and their role in human tumourigenesis. Biochim Biophys Acta. 2007;1776(1):58-85.

13. Donninger H, Vos MD, Clark GJ. The RASSF1A tumor suppressor. J Cell Sci. 2007;120(Pt 18):3163-3172.

14. Hesson LB, Cooper WN, Latif F. The role of RASSF1A methylation in cancer. Dis Markers. 2007;23(1-2):73-87.

15. Simons A, Shaffer LG, Hastings RJ. Cytogenetic nomenclature: changes in the ISCN 2013 compared to the 2009 edition. Cytogenet Genome Res. 2013;141(1):1-6.

16. Slovak ML, Kopecky KJ, Cassileth PA, et al. Karyotypic analysis predicts outcome of preremission and postremission therapy in adult acute myeloid leukemia: a Southwest Oncology Group/Eastern Cooperative Oncology Group Study. Blood. 2000;96(13):4075-4083.

17. Liu F, Gao L, Jing Y, et al. Detection and clinical significance of gene rearrangements in Chinese patients with adult acute lymphoblastic leukemia. Leuk Lymphoma. 2013;54(7):1521-1526. 
18. Shen Y, Zhu YM, Fan X, et al. Gene mutation patterns and their prognostic impact in a cohort of 1185 patients with acute myeloid leukemia. Blood. 2011;118(20):5593-5603.

19. Guan L, Gao L, Wang L, et al. The frequency and clinical significance of IDH1 mutations in Chinese acute myeloid leukemia patients. PLoS One. 2013;8(12):e83334.

20. Chen TC, Hou HA, Chou WC, et al. Dynamics of ASXL1 mutation and other associated genetic alterations during disease progression in patients with primary myelodysplastic syndrome. Blood Cancer J. 2014;4(1):e177.

21. Haferlach T, Nagata Y, Grossmann V, et al. Landscape of genetic lesions in 944 patients with myelodysplastic syndromes. Leukemia. 2014;28(2):241-247.

22. Itzykson R, Kosmider O, Renneville A, et al. Prognostic score including gene mutations in chronic myelomonocytic leukemia. J Clin Oncol. 2013;31(19):2428-2436.

23. Yang J, Schiffer CA. Genetic biomarkers in acute myeloid leukemia: will the promise of improving treatment outcomes be realized? Expert Rev Hematol. 2012;5(4):395-407.

24. Murati A, Brecqueville M, Devillier R, Mozziconacci MJ, GelsiBoyer V, Birnbaum D. Myeloid malignancies: mutations, models and management. BMC Cancer. 2012;12:304.

25. Shih AH, Abdel-Wahab O, Patel JP, Levine RL. The role of mutations in epigenetic regulators in myeloid malignancies. Nat Rev Cancer. 2012;12(9):599-612.

26. Jasielec J, Saloura V, Godley LA. The mechanistic role of DNA methylation in myeloid leukemogenesis. Leukemia. 2014;28(9):1765-1773.

27. Smith BD, Beach CL, Mahmoud D, Weber L, Henk HJ. Survival and hospitalization among patients with acute myeloid leukemia treated with azacitidine or decitabine in a large managed care population: a real-world, retrospective, claims-based, comparative analysis. Exp Hematol Oncol. 2014;3(1):10.

28. Yun S, Vincelette ND, Abraham I, Robertson KD, FernandezZapico ME, Patnaik MM. Targeting epigenetic pathways in acute myeloid leukemia and myelodysplastic syndrome: a systematic review of hypomethylating agents trials. Clin Epigenetics. 2016;8:68.
29. Ding K, Fu R, Liu H, Nachnani DA, Shao ZH. Effects of decitabine on megakaryocyte maturation in patients with myelodysplastic syndromes. Oncol Lett. 2016;11(4):2347-2352.

30. Griffiths EA, Gore SD, Hooker C, et al. Acute myeloid leukemia is characterized by Wnt pathway inhibitor promoter hypermethylation. Leuk Lymphoma. 2010;51(9):1711-1719.

31. Johan MF, Bowen DT, Frew ME, Goodeve AC, Reilly JT. Aberrant methylation of the negative regulators RASSFIA, SHP-1 and SOCS-1 in myelodysplastic syndromes and acute myeloid leukaemia. $\mathrm{Br} J$ Haematol. 2005;129(1):60-65.

32. Avramouli A, Tsochas S, Mandala E, et al. Methylation status of RASSF1A in patients with chronic myeloid leukemia. Leuk Res. 2009; 33(8):1130-1132.

33. Paschka P, Schlenk RF, Gaidzik VI, et al. ASXL1 mutations in younger adult patients with acute myeloid leukemia: a study by the GermanAustrian Acute Myeloid Leukemia Study Group. Haematologica. 2015; 100(3):324-330.

34. Shivarov V, Gueorguieva R, Ivanova M, Tiu RV. ASXL1 mutations define a subgroup of patients with acute myeloid leukemia with distinct gene expression profile and poor prognosis: a meta-analysis of 3311 adult patients with acute myeloid leukemia. Leuk Lymphoma. 2015;56(6): 1881-1883.

35. Schnittger S, Eder C, Jeromin S, et al. ASXL1 exon 12 mutations are frequent in AML with intermediate risk karyotype and are independently associated with an adverse outcome. Leukemia. 2013;27(1):82-91.

36. Odenike O, Thirman MJ, Artz AS, Godley LA, Larson RA, Stock W. Gene mutations, epigenetic dysregulation, and personalized therapy in myeloid neoplasia: are we there yet? Semin Oncol. 2011;38(2): 196-214.

37. Takahashi S. Current findings for recurring mutations in acute myeloid leukemia. J Hematol Oncol. 2011;4:36.

38. Gill H, Leung AY, Kwong YL. Molecular targeted therapy in acute myeloid leukemia. Future Oncol. 2016;12(6):827-838. 


\section{Supplementary materials}

Table SI Primers and probes for detection of MYODI and RASSFIA methylation levels

\begin{tabular}{lll}
\hline Gene & Designation & Sequence $\left(\mathbf{5}^{\prime} \mathbf{- 3}^{\prime} \mathbf{)}\right.$ and labeling \\
\hline MYODI & Forward primer & GTGATAAAATATTAAATGTGTTTGGTAAGTTTA \\
MYODI & Reverse primer & ATTTTTCTAAAAACTTCCTCAAAACTATCATC \\
MYODI & FAM-MGB probe & ATTGTAAAGGTAATTTGATGATAG \\
RASSFIA & Forward primer & TGGTTTTTAGAAATACGGGTATTTTCGCGTG \\
RASSFIA & Reverse primer & AAAACCCGAAAACGAAACTAAACGCGCT \\
RASSFIA & FAM-MGB probe & CGTGGTGTTTTGCGGTCGTCGTCGT \\
\hline
\end{tabular}

Table S2 Primers and probes for detection of ABLI and RASSFIA mRNA levels

\begin{tabular}{lll}
\hline Gene & Designation & Sequence $\mathbf{( 5}^{\prime} \mathbf{- 3} \mathbf{3}^{\mathbf{\prime}}$ and labeling \\
\hline$A B L I$ & Forward primer & AGGCTGCCCAGAGAAGGTCTA \\
$A B L I$ & Reverse primer & TGTTTCAAAGGCTTGGTGGAT \\
ABLI & FAM-MGB probe & TGGAATCCCTCTGACCGG \\
RASSFIA & Forward primer & CCTGCATGTGCTGTCACGCACAAGG \\
RASSFIA & Reverse primer & CTCATCATCCAACAGCTTCCGCAAGTACAC \\
RASSFIA & FAM-MGB probe & CACGTGAAGTCATTGAGGCCCTGCTG \\
\hline
\end{tabular}

Table S3 Primers of gene mutations for sequencing

\begin{tabular}{|c|c|c|}
\hline Gene & Primer F $\left(5^{\prime}-3^{\prime}\right)$ & Primer R $\left(5^{\prime}-3^{\prime}\right)$ \\
\hline \multirow[t]{5}{*}{ ASXLI } & TGATGCTGCCTCGAGTTGTC & TTGGTCAAACCCAGCTTCTGT \\
\hline & AGAAGCTGGGTTTGACCAAAGA & GTGGCTTTTCGGTGTGAACA \\
\hline & CCCCGGCTTGAAGATCGT & GTGAGTCCAACTGTAGCCCTCTGT \\
\hline & GGCACCACTTCCTGGGAAA & TGCTTCAGAGTCTCCGTTGATTT \\
\hline & GAGGCCACTAACCCACTTGTG & CCCTTGGCCTGTAACATTGC \\
\hline \multirow[t]{2}{*}{ DNTM3A } & GAAGACCCCTGGAACTGCTACA & GAAGTAGCGGGCCCTGTGT \\
\hline & TCTACCGCCTCCTGCATGAT & TGGGTGCTGATACTTCTCTCCAT \\
\hline FLT3 & TCCTGTTTCTCGGATGGATACC & TGGGTCATCATCTTGAGTTCTGA \\
\hline NRAS & GCCGCATGACTCGTGGTT & GGCGTATTTCTCTTACCAGTGTGTAA \\
\hline \multirow[t]{3}{*}{ SF3BI } & TCAACACTTAGTCCAGAAGAGCAAA & АСTTTCTGCTGCTCATCCACAA \\
\hline & GCCATCTTGCCACATCTTAGAAGT & CCATCAATCAGTTGTTCTTCAAGTTT \\
\hline & ТСТТССТСССТTTTTTAАAСАСТTСТ & GTGGAGTCATCTTATGCATACCTATGA \\
\hline SRSF2 & CGACGCTGAGGACGCTATG & AAGACCTACCCCAAATCCCATT \\
\hline \multirow[t]{3}{*}{ TET2 } & ATCACTCACCCATCGCATACC & TCATTGTCCCTGCAGTCTGTATGT \\
\hline & ATGACATACAGACTGCAGGGACAA & TGTTGCAAAAGGTGTGAGTTTGA \\
\hline & CCAGTGTTGAAACAGCACTTGAA & GGCACAGGAAAAACATTTGCA \\
\hline KIT & TACATGGACATGAAACCTGGAGTT & AATGGTCTACCACGGGCTTCT \\
\hline NPMI & AGGAGGAGGATGTGAAACTCTTAAGTAT & AACACGGTAGGGAAAGTTCTCACT \\
\hline CEBPA & AAGAAGTCGGTGGACAAGAACAG & GCAGGCGGTCATTGTCACT \\
\hline RUNXI & GTCATTTCCTTCGTACCCACAGT & GTGTGGGCTGACCCTCATG \\
\hline U2AFI & TGTGGAGATGCAGGAACACT & AATGGCATGGCTCAGAATCG \\
\hline IDHI & CCAAGTCACCAAGGATGCTG & CCATGTCGTCGATGAGCCTA \\
\hline
\end{tabular}

\section{Publish your work in this journal}

OncoTargets and Therapy is an international, peer-reviewed, open access journal focusing on the pathological basis of all cancers, potential targets for therapy and treatment protocols employed to improve the management of cancer patients. The journal also focuses on the impact of management programs and new therapeutic agents and protocols on

\section{Dovepress}

patient perspectives such as quality of life, adherence and satisfaction. The manuscript management system is completely online and includes a very quick and fair peer-review system, which is all easy to use. Visit http://www.dovepress.com/testimonials.php to read real quotes from published authors. 